\title{
Cultural Sustainability in the Creative Surface Design of Fashion Products of Eco-Textile and Eco-Leather Material Structures
}

\author{
Marlena Pop* \\ National Research and Development Institute for Textile and Leather (INCDTP), Romania
}

*Corresponding author: Marlena Pop, National Research and Development Institute for Textile and Leather (INCDTP), Bucharest, Romania.

Received Date: September 09, 2019

Published Date: September 16, 2019

\section{Abstract}

The concept of cultural sustainability of products is based on the principle of their durability in time, which requires a slowdown in serialization, production and consumption, and an increase in added value and creative personalization, with emphasis on cultural identity visual semiotics.

The concept of cultural sustainability of products is more largely applied in industry and visual culture, having as fundamental tools the imaginary of each cultural heritage, Basically the whole arsenal of cultural anthropology of humanity along with individual creativity and imagistic prognoses of new ecological philosophical concepts [1,2]. From the point of view of a scientific discourse on the culture of sustainability, it can be demonstrated by the state-of-the-art in the field of textile design that this is necessary both at the level of the academic institutions in which the future designers are trained, and in the economic, industrial and social environment in which both makers and consumers of these products are found.

Surface Design is an interface between material, technology and consumer, being both a scientific and technical interface and a socio-cultural one. On the substrate of a raw, ecologic material by its nature, processing technologies operate bringing a high-quality material structure to the semiprocessed stage for the creative industries where the fashion industry is an important cultural peak. As a semi-processed product, leather expresses only its value as a material, because the added value is only reflected by an efficient surface design. Surface design is not just a type of finish, it is an art-science act that, if well-known and coordinated, can be spectacular and sustainable at the same time [3].

Creative Design Laboratory experiments conducted by interdisciplinary teams with researchers and students in the visual arts, will highlight the structure of cultural sustainability in fashion products, associated with the scientific sustainability of textile and leather structures, oriented towards the ecology of materials [4].

Keywords: Cultural sustainability; Eco textile; Eco leather; Creative surface design

\section{Introduction}

In order to obtain durable models in a circular economy, circular economy specialists are currently focusing on design creation, on system creation, on LCS creation, on a systemic thinking of recycling and waste management. Although, al local level, there are notable cases of success in various European industries, no notable results can be identified at regional level. With all these small successes achieved at local level, one can see, at regional level, the three pillars indicating the growth of a durable economy, stated in the EU 2030 Agenda - e.g. the environmental, the economic and the social pillars [5].

The socio-cultural benefits are more difficult to see, but the three pillars stated above cannot function without the contribution of the fourth, which is the culture, because it represents the footprint of anthropization, which must also be durable. There are numerous studies showing that Circular Economy programmes fail to take into account the social dimension of such systems' sustainability [6]. However, market research studies and consumer preference analyses, particularly those focusing on green products, green systems or green markets, reveal just how straight forward the influence of the sustainability culture or the cultural sustainability of products can be on each person. The Liberal thinking focuses on pluralism, interdependence and globalization, the constructivist approach is focused on language, symbols and images, both those belonging to the real world and those belonging to the digital environment, while the Realist thinking focuses on 
technology development, safety, security and pragmatism [7]. This philosophical approach to green products, processes and markets generates the idea of a culture of sustainability. However, this term of culture, in itself, is so wide (just like art) that it becomes almost impossible to define without a context, or without an identitybased approach (the Indian Culture, the American Culture, the national culture, the regional culture, etc.). The synergic approach to the generic elements taken from the three philosophical theories used in economy - the liberal theory, the structural theory and the realist theory - and the implementation of these elements in the conceptualization practice specific to creative textile design, can only be of great help in an open system like arts. The immaterial dimension of modern culture is used in marketing as a working tool for understanding people's relationship with creative and cultural objects. The relationship between product experience and aesthetic values is important in the context of cultural studies, "because implicit and explicit values are often seen as key determinants of culture" [3] [8]. In this context, of articulating the human experience with the practical, more technical environment of design, if we want to understand emotional design as consumercentered practice, it is necessary to understand the content and the imaginative meaning of the design concept [9]. Practically, by reading the aesthetics of design, by understanding the metaphor or visual metonymy, the aesthetic emotion is achieved, which gives the feeling of aesthetic pleasure. Paul Hekkert [10] reported that "proposes to restrict the term aesthetic to the pleasure attained from sensory perception, as opposed to anesthetic. An experience of any kind, e.g., of an artwork, a product, a landscape, or an event, thus comprises an aesthetic part, but the experience as a whole is not aesthetic".

Surface design is an interdisciplinary working environment, for the section of $0.6-1.5 \mathrm{~mm}$ in the structure of materials. This environment called finishing, texture, touch, in which materials science is combined with the technologies of hide processing and finishing, the theory and practice of product design, in which the cultural sustainability component clearly expresses the aesthetic and socio-human value of the product, represents, basically, the motivation of a purchase decision. Thus, Surface Design is an interface between material, technology and consumer, being both a scientific and technical interface, as well as a socio-cultural one [11].

From the designer's perspective, the textures can be naturally macroscopic. These can be inspirational in creating a texture, finding numerous inspiration sources in nature, heritage or technological artifacts. They can be naturally microscopic because the nanometric universe of biological as well as inorganic matter is immeasurable [12]. This represents an inexhaustible inspirational source of great interest in surface design research. Textures can be visual, from an artistic point of view, and their characteristics are given by thematic, descriptive, symbolic or inspirational subjects in the visual arts. The tactile texture is the one that has a 3D surface specific to some artistic techniques, to a plastic technical style, such as brush stroke, pressing in animal print. In visual art and design, "texture defines the surface of the work created" [13]. Surface design is the process by means of which chemical, mechanical or artistic modeling of the surfaces leads to innovative, creative or simply original textures. It "makes the surface or substance feel or look different in color or shape, regardless of whether the surface is rough, smooth, robust or silky". The artistic and technical characteristics of textures evolve at the same time and in the same direction with art and design trends, from the real texture of the materials to the innovative, artistic or technical texture.

Visual texture is the sensation perceived from the surface of the materials or artificial creations, defined by Pipes as something "created by the artist's hand", which specifies the two-dimensional surface texture involved in art and design. There is no tactile sense that can be perceived from the visual texture which is an important and developable element in two-dimensional fields. Visual texture shows a creative activity performed by artists and designers using their imagination.

Textile and Leather is a natural and durable material, unmatched by any synthetic product in terms of hygienic and protective properties. On the substrate of a raw, ecological material, by its nature [14], processing technologies work by bringing a highquality material structure to the semi-processed stage for creative industries where the fashion industry is an important cultural peak. Processing of the oldest fiber- based material used for human clothing combines the highest knowledge in chemistry with the traditional craft. The challenge regarding the sustainability of textile and leather processing involves important steps from the conservation of the raw materials to wet finishing and the more ecological finishing of the surface through the use of nanomaterials [15]. Defining the concept of surface design and its practical interpretations, demonstrated by a technological, scientifically emergent and artistic approach is a good basis for identifying aspects related to the cultural and technical sustainability of textile and leather products in the fashion sector.

\section{Design Methodology}

The development of a cultural sustainability framework, both in the textile industry, as a beneficiary of textile design concepts and in the professional design environment, needs a synergic approach to sustainable material basis, which has to be taken into account by each designer, when they conceptualize a product and use the method of cultural mixed instruments [16]. The content/ expression - meaning/language binomial duo is used by designers as a working tool.

The content instruments in design are imaging with philosophical meaning, visual archetypes, visual cultural items. Cultural expression elements are defined by the syntax and the style of the artistic language, which have to be specific in their way of expression. Transversal creation actions provided by the visual language use both content codes and the aesthetic material basis, by means specific to the visual language, as an instrument of cultural expression. Method aspects include the following: 
- definitions, types and cognitive schemas of research in the practice of art and textile design, surface design of the textile and leather for fashion;

- The structure of the research in design and the process of its development in the stages of ideas and creation of new product concepts - "Design Thinking” tool;

- Definition and types of cultural instruments used in product creation and design: international textile trends, inclusive and identity themes and awareness of personal creativity;

- Definition, typology and examples of identity design;

- What is and what is the importance of the ethnic culture as a tool for developing the cultural sustainability of modern products;

- Experimental methodology that aims primarily to use cultural content tools and to perform transversal actions of visual conceptual hybridization.

By explaining the stages of ideas and conceptualization used for the team and for individual projects, the students were easier to follow the steps of the method and the work became more relaxed and continuous. By activating the ideation processes, one can bring in new aesthetic elements, both by way of innovation and by using a creative diversity of aesthetic concepts. Thus, in order to turn an idea obtained this way, into a product concept, one needs to implement transversal actions, acts of stylistic and commercial sorting declination [17], as well as actions meant to complete the entire design project elaboration process. Thus, this process of design thinking, employing cultural instruments, helps develop a wider variety of cultural objects and creative products, turning a specific material into an emotional and cultural product [18].

\section{Experiments}

The Experiments carried out in the artistic lab, by the Bucharest National University of Arts, Department of Textile Arts and Textile Design. During this process, the aim was to develop both vertically, by gaining new knowledge and innovation and horizontally [19], via the diversity of the artistic expressions used in certain well positioned and competitive textile design projects developed in the field of cultural product sustainability [20].

\section{Techniques in textile surface design}

Tapestry/ creative weaving/digital design of contextures: The experiments carried out in the art of weaving, which is one of the oldest artistic technologies in the world, has always allowed some truly remarkable artistic performances to be achieved. The Tapestry manufactured using the haute lisse technique is a polychrome landscape weaving executed on a vertical loom. The tapestry's surface is not smooth: each netting thread creates a small grey shadow (striation) in the narrow groove separating it from its neighboring thread, thus increasing the colour diversity. Another feature characterizing the haute lisse tapestry is the fact that the cross-fibres do not necessarily go across the entire width of the fabric, but only across a certain number of netting threads, enough to cover the same-colour decoration motive. This classic tapestry experiment uses the haute lisse technique, which is a sustainable technique both from a cultural, and from a material viewpoint. It has given the author the chance to transpose an emotion and an artistic research issue, an issue of expressing a direct emotion in a decorative manner, upon direct contact with the speleological world, counting on the psychological effect of a dialogue with the public. "Speleotema" a semester project, author: Delia Ciubotaru, license student UNArte (Figure 1a).

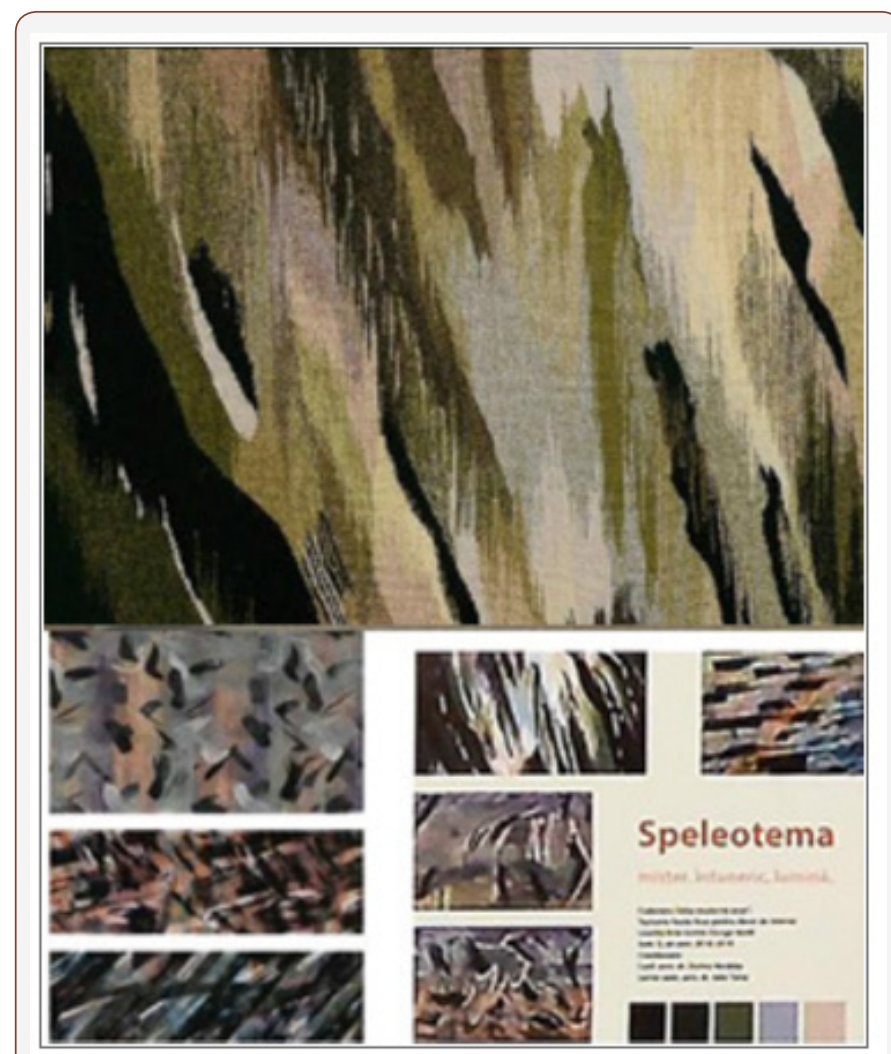

Figure 1a: Tapestry/ Haute -lise.

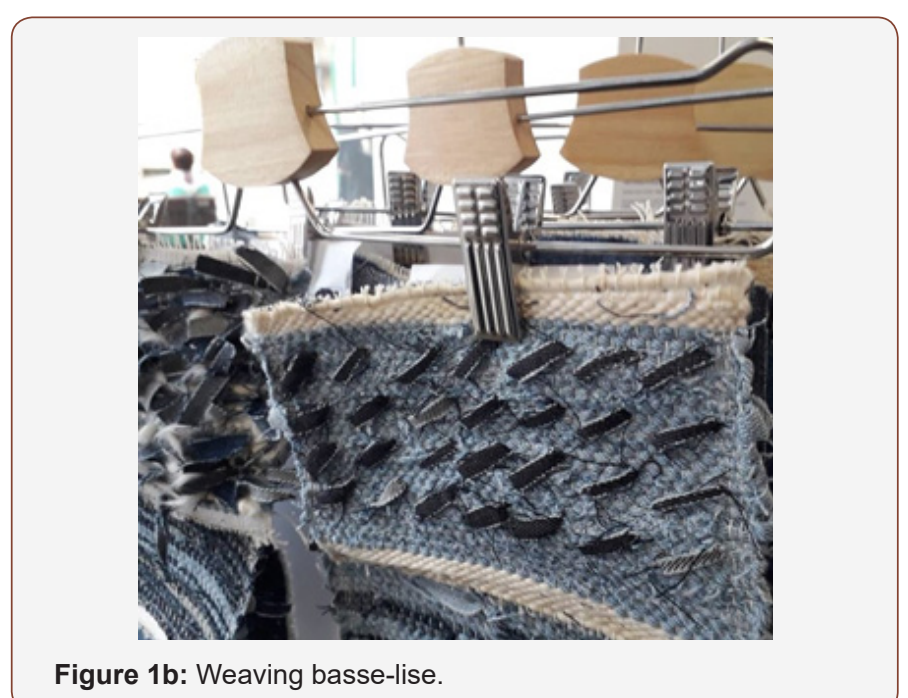

Creative weaving is the experimental use of the basse-lise technique for creating multiple forms of textile knots and weaving discontinuities that produce original aesthetic effects. Some of 
these experiments may lead to the development of digital design programs for fashion contextures. Being a source of digital creativity development, experimental creative weaving is always needed in creative design. Figure $1 \mathrm{~b}$ shows experiments in creative design, using the basse-lise technique of third year students from Arts \& Textile Design BA Programme, 2018, under the coordination of associate professor dr. Dorina Horatau, UNArte Bucharest.

Serigraphy: Serigraphy, as an art of printing and template, is thousands of years old and it had been sustainable until 100 years ago, when synthetic dyes, inks and pastes started being used. Thus, due to its versatility, it can always be both a creative matter and the heart of an ecological design project. The only condition is related to the chemical structure of the inks used and the technical fixation processes. Manual serigraphy on flat textile fabric is a process used to execute various decorations printed on various types of smooth surfaced material or textile items. Serigraphic nets are manufactured using photo-sensitive emulsions, based on a handmade drawing or on a computer- made graphic of the model that has to be imprinted (one net for each colour comprised in the printing template). Examples: "Diafan" (Diaphanous), Undergraduate, $1^{\text {st }}$ year, semester work, author: Mihaela Sîrbu, UNArte, Bucharest. (Figure 2).

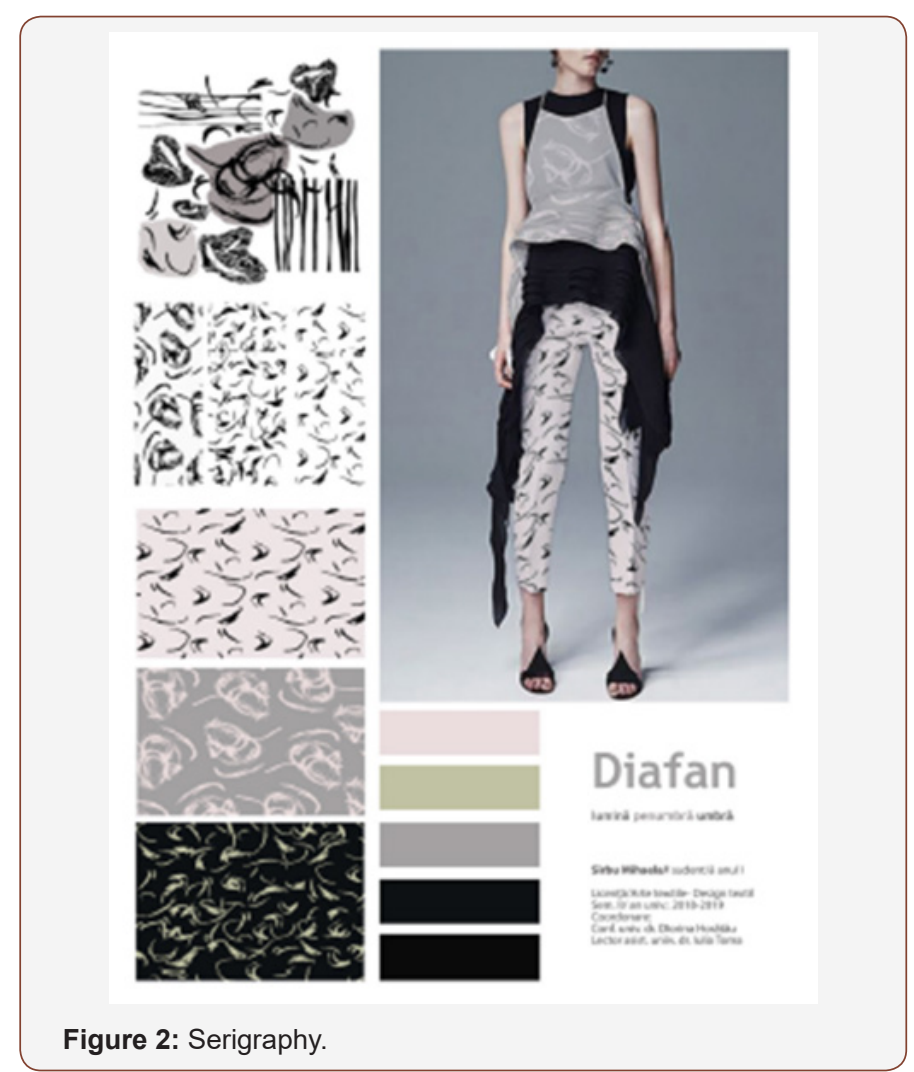

Sewing/ Embroidery: Sewing is the second sustainable cultural technology, after weaving, that is several millennia old can still pass on various values of different identity cultures, thus being a vector of our cultural inheritance. The traditional Popular Romanian outfits worn on Sundays and holidays (especially the shirts and women's blouses (in Romanian: i.e.)) bear decorations sewn in cross-stitching technique, which has the great advantage of being easy to execute and the cultural advantage of being artistically and spiritually assimilated to the idea of Christianity, the dominant religion in Romania. The stitching point is made of two overlapping oblique lines (one going from left to right and the other one, the other way around, from right to left) on the outside, while, on the inside, two vertical lines are formed. The dissertation paper titled "Retrospection", author: Mirela Iordache, UNArte, Bucharest is a good example of sustainable valorization of an identity semiotic element and a good exemplification of a technique that has remained sustainable until today (Figure 3a).

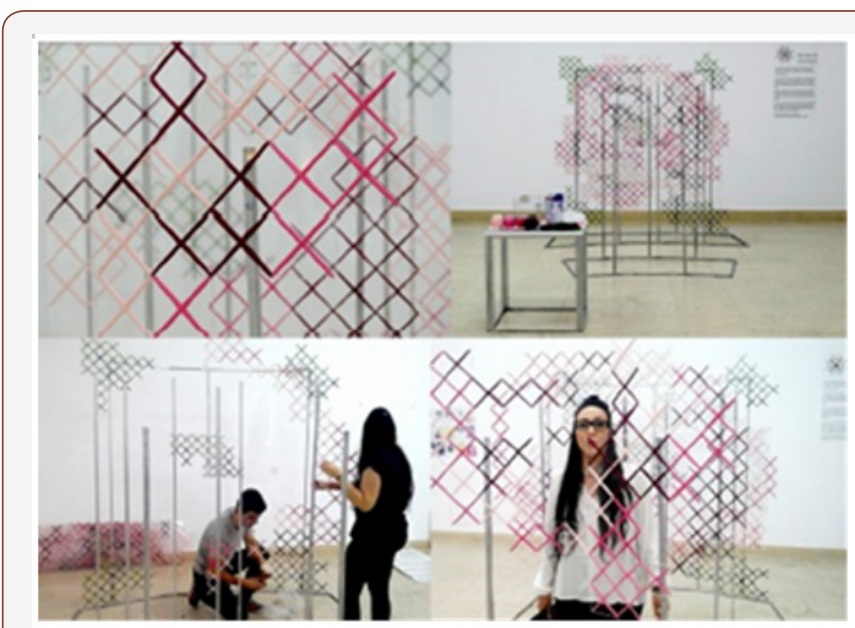

Figure 3a: Textiles installation with semiotic identity element from sewing - "cross".

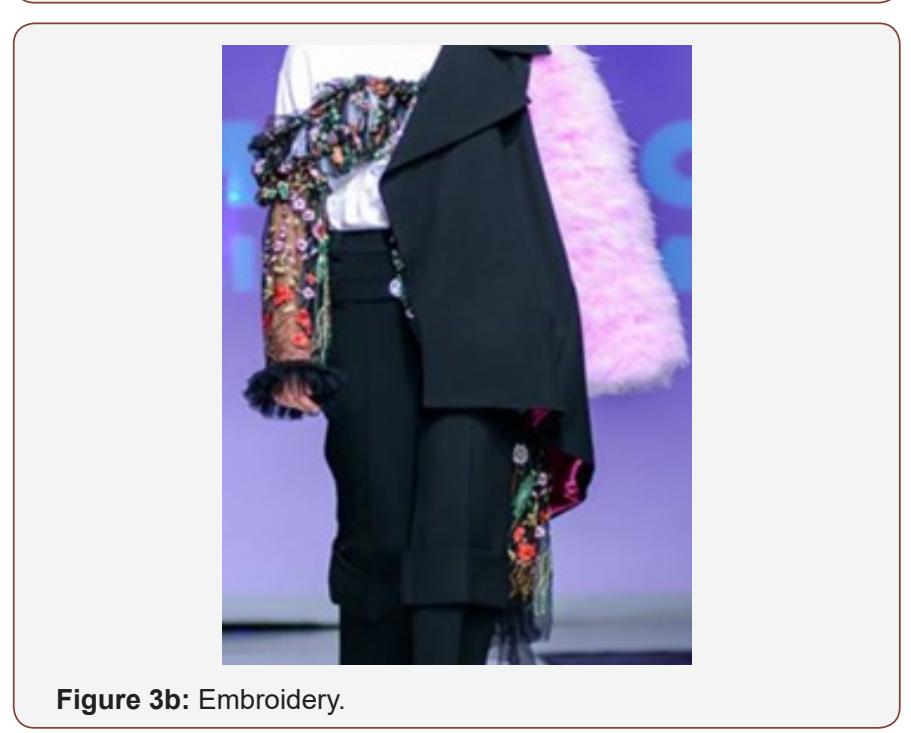

Embroidery, as a form of artistic excellence through sewing, has an old tradition, of Byzantine influence, in the Balkan area of Europe. It's strictly aesthetic role, to beautify fabrics in order to facilitate the identification of the wearer's status, has been preserved until today. Figure $3 \mathrm{~b}$ presents an experiment of the $3^{\text {rd }}$ year student in Fashion Design BA Programme, Lucian Arsene, with prof. Dr. Paula Barbu as coordinator.

Mixed techniques: The artistic directions of this postmodernist century are very versatile, thus becoming mixed techniques, especially in the field of surface design. Their plastic ways of expression, using sustainable textile fabrics, can apply to various domains: fashion, architecture, the ambient. Surface 
design is a type of textile surface modelling focused primarily on spectacular elements.

This working technique required various types of interventions on the textile fabric (serigraphic printing, sewing, tearing, embroidering, textile collage, cutting, folding, etc.) During the art and design sustainability experiments, carried out with the textile design specialty students within UNA Bucharest, several material assemblies have been created for fashion purposes. A very good example of this is the semester work tilted "Fancy", author Ioana Tabacaru (Figure 4).
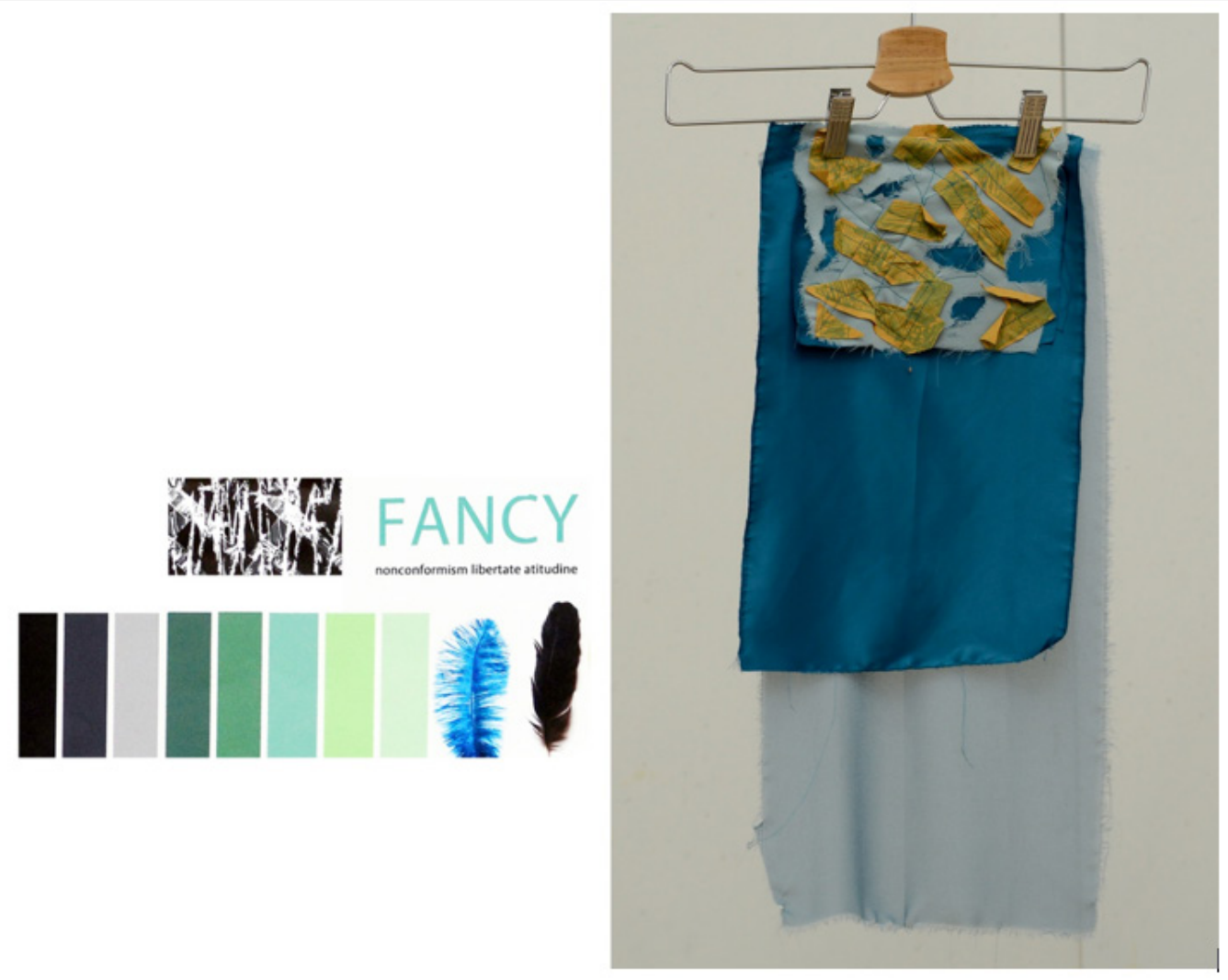

Figure 4: Mixed techniques.

Digital Printing: Printing on a textile fabric is a modern alternative to the traditional ways of imprinting (serigraphy or rotary). Today's digital technology allows high fidelity colour printing on organic materials (natural fibres) or on artificial materials (for instance, printing pictures). The ink used penetrates the fabric without being felt upon touching and it is highly resistant to stretching and to successive washing. The "FIELD essence", a $1^{\text {st }}$ year Master's project (semester assignment), author: Ruxandra Chivu, UNArte, Bucharest, is an indoor textile design solution, comprising three sub- collections of textile upholstery projects, where image-processing computer programmes were used (such as Adobe Illustrator, Adobe Photoshop CS/ versions 4 - 5) (Figure 5).

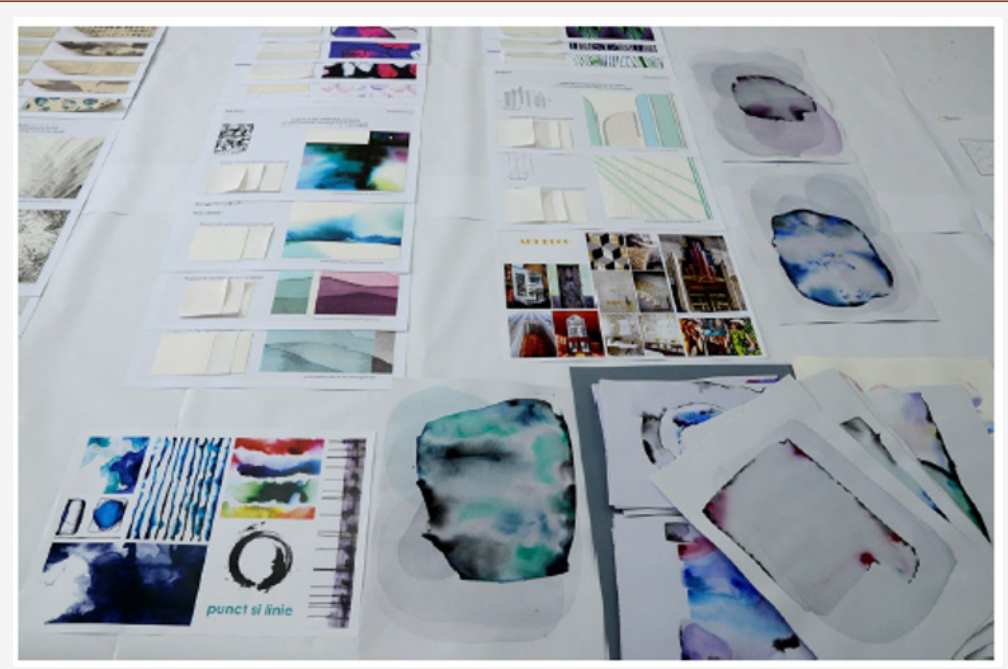

Figure 5: Digital Print. 
Leather surface design: In the field of fashion, changing textures through artistic techniques of printing, profiling, pressing, mixed techniques, through innovative concepts of chromatics, graphics, meaning and message, leads to the development of a new aesthetic ideal, a fashion theme or an original fashion project. This transforms any texture created in the field of surface design into a fashionable commercial product. The abstract texture, as the name suggests, is created through abstract work and modified with a hint of the original texture to meet the creator's intention. Abstraction mainly involves visual simplification and sometimes exaggeration. The abstract texture is the symbolization of an original object and has the function of decoration and can tell its observers what they see. Figure 6 shows an abstract floral texture. It is not a digital reproduction of a baroque picture or a bouquet of flowers, but the art nouveau stylistic interpretation of a bouquet of flowers. The degree of abstraction is not total because the image is figurative. The scale from the figurative naturalist to the total abstractionism has several degrees of semiotic and stylistic personalization that has generated the whole history of the visual arts. Creating surface texture is an open innovation process, which can be achieved through multiple techniques and methods. Compared to color, texture is less affected by fashion trends and has more room for creativity. In general, texture and color form the appearance of the surface. Compared to the line, shape and space, the texture is more flexible in terms of physical factors, wear ability and object function.

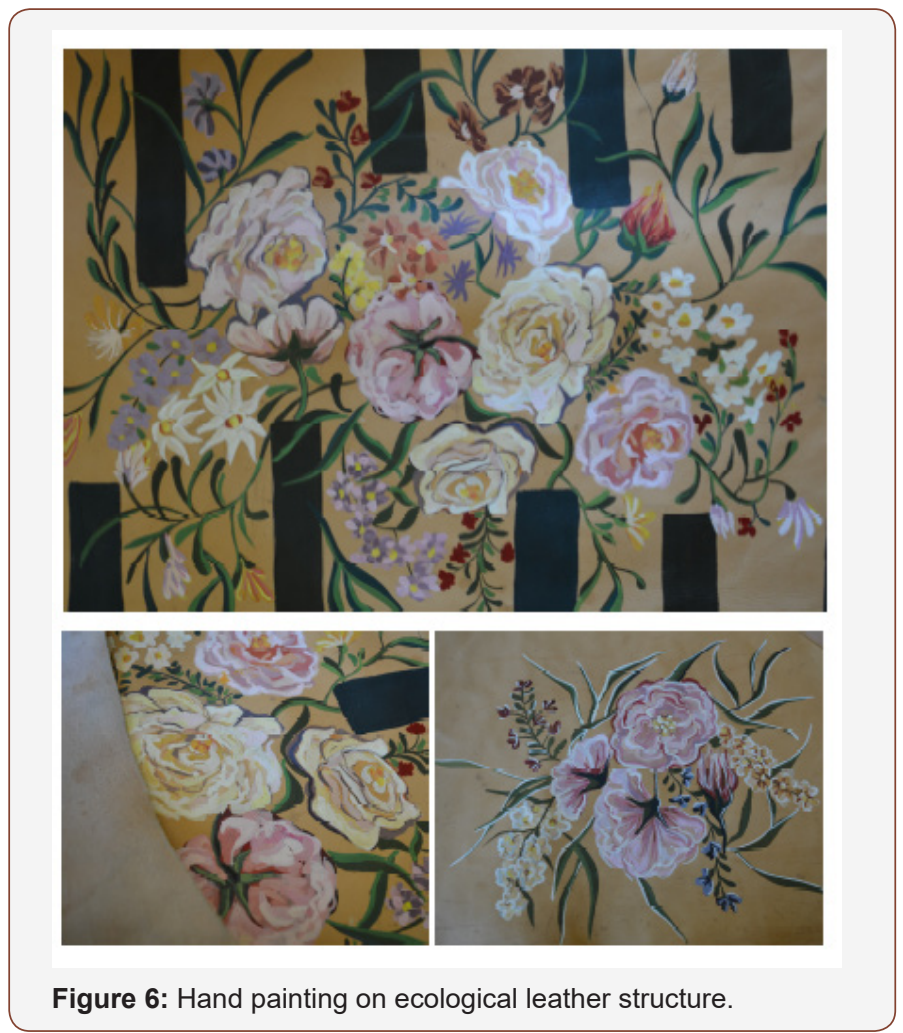

\section{Conclusion}

It can be concluded that the need to use in a versatile but efficient manner, the concepts of cultural sustainability and the culture of sustainability, needed to develop bio/eco/organic products, refers to: A holistic approach to managing the design of the product sustainability concept in such way to make sure that its four crucial parameters: the environment, the economy-technology, the social aspect and the culture - coexist in each sustainable product created.

Developing sustainability of textile and leather processing technologies implies that the creation of an innovative technical niche will highlight the sustainable scientific and cultural aspects; Although the aesthetic and cultural elements are dominant in surface design, textile, leather fashion products, made in the slow fashion manner, but it can be ecological if the technical and scientific matrix of the material structure can be shown to be ecological.

- Surface design of the textile and leather product for fashion is a field of sustainable design if a practice of interdisciplinary collaborative research between chemistry-technology-design is developed.

- The concept of sustainability culture must become a vector of sustainable education strategies, in all society structures.

- The attention given to products' cultural sustainability can only be visible if there is an active culture of sustainability in place.

- The concept of cultural sustainability of products, processes and organizations must lead, via its good practices, to the development of a Circular Economy.

\section{Acknowledgement}

This scientific paper is funded by the Romanian Ministry of Research and Innovation within Program 1 - Development of the national RD system, Subprogram 1.2 - Institutional Performance RDI excellence funding projects, Contract no. 6PFE/2018.

\section{Conflict of Interest}

Authors declare no conflict of interest.

\section{References}

1. Douglas M, Isherwood BC (1996) The world of goods: Towards an anthropology of consumption ( $2^{\text {nd }}$ edn). London, Routledge, UK.

2. Pop M, Iuhas F, Borangic C (2016) Repertoriul Imagistic Roman, Ed incdtp-icpi Bucharest, Romania

3. (2011) Eco-Design: Life Cycle analyses show that energy is a key factor for the environmental impact of leather and might save money, T. Poncet et al. IULTCS Congress.

4. Buljan J, Král' I (2015) The framework for sustainable leather manufacture. The United Nations Industrial Development Organization.

5. Council of the European Union (2017) A sustainable European future: The EU response to the 2030 Agenda for Sustainable Development, Press Release Database, Brussels, Belgium.

6. Directive UE (2015) Circular Economy Package: Questions \& Answers, European Commission Press Release Database, Brussels, Belgium.

7. Eriksson J, Giacomello G (2006) The Information Revolution, Security, and International Relations (IR) relevant Theory? International Political Science Review 27(3): 221-244.

8. Desmet P, Hekkert P (2007) Framework of Product Experience. International Journal of Design 1(1): 57-66. 
9. Hassenzahl M (2010) Experience design: Technology for all the right reasons. Journal: Synthesis Lectures on Human-Centered Informatics: $1-95$.

10. Hekkert P (2006) Design aesthetics: principles of pleasure in design. Psychology Science 48(2): 157-172.

11. Niculescu O, Coară G, Chelaru C, Gurau D (2018) New Products Based on Essential Oils for Finishing Natural Leathers with Antifungal Performances. The $7^{\text {th }}$ International Conference on Advanced Materials and Systems. 281-286.

12. Gaidau C, Petica A, Trandafir V, Ciobanu C, Martinescu T (1996) Nano silver Application for Collagen Based Materials Treatment, The $\mathrm{XXX}^{\text {th }}$ International Congress IULTCS Beijing 11-15 October 2009 Durand, G. Introduction à la mythodologie: Mythes et sociétés, Editions Albin Michel, SA.

13. O'Sullivan T, et al. (1994) Key Concepts in Communication and Cultural Studies. ( $2^{\text {nd }}$ edn), London: Routledge.

14. Olga N, Minodora L, Teodora S, Zenovia M, Ciprian C, et al. (2015) Obtaining and Characterization of Some Ecologic Pigment Pastes for
Finishing Natural Leather and Furs. Revista de Chimie, Bukarest 66(9): 1278-1281.

15. Gaidau C, Petica A, Ignat M, Iordache O, Ditu LM, et al. (2016) Enhanced photocatalysts based on $\mathrm{Ag}-\mathrm{TiO}_{2}$ and $\mathrm{Ag}-\mathrm{N}-\mathrm{TiO}_{2}$ nanoparticles for multifunctional leather surface coating. Open Chem 14(1): 383-392.

16. Pop M, Horatau D (2019) Cultural sustainability and archetype in creative textile design, The Fourteenth International Conference on The Arts in Society, PI Lisbon, Portugal.

17. Pop M,Toma S, Frigy N (2018) Cultural work instruments in fashion technology - practical method of generating emotional design. J Textile Sci \& Fashion Tech 1(1): 1-7.

18. Weber C (2005) International Relations Theory. A critical introduction. $\left(2^{\text {nd }}\right.$ edn), Routledge, Taylor \& Francis group, USA, pp 1-222.

19. Foucault M (1980) Power/Knowledge. Hemel Hampstead: Harvester Wheatsheaf.

20. Stuart H (edt.) (1997) Representations: Cultural Representations and Signifying Practices. Milton Keynes: Open University Press, UK. 